\title{
CONTINUOUS PERIODS FOR HARVESTING SCHEDULES: A NUMERICAL APPLICATION FOR THE BRAZILIAN SUGARCANE INDUSTRY
}

\author{
José Vicente Caixeta-Filho $^{1^{*}}$ and André Eidi Miyashita ${ }^{2}$ \\ Received August 9, 2017 / Accepted September 15, 2018
}

\begin{abstract}
This study was developed to maximize revenue from commercialization of sugar by optimizing the crop harvest within continuous scheduling periods subject to constraints on processing capacity and minimum proportion of farm area to be harvested. Specific constraints were developed to guarantee the continuity of the harvesting calendar per farm. The mathematical model employed is based on a Mixed Integer Linear Programming structure (MILP). Scenario analyses were conducted with the proportion of the farm to be harvested altered. An important finding was that a harvest scheduling pattern emerged as the proportion of the farm's land to be harvested increased, being this pattern broken when the minimum harvested area increased to $33 \%$ of the farm's cultivable area. Results are also useful for the evaluation of the feasibility of movement of equipment during harvesting operations.
\end{abstract}

Keywords: sugarcane, optimization, harvesting, scheduling.

\section{INTRODUCTION}

The Brazilian economy is strongly based on the primary sector, mainly agricultural and agribusiness activities. These activities are become more technically sophisticated and professionally managed over recent years as a response to a combination of an increasingly competitive economic environment and the dissemination of advanced techniques and technologies.

In order to improve revenues in agribusinesses' sugar chain, Supply Chain Management (SCM) has become increasingly in focus. SCM investigates and measures chain related problems to develop best practices and techniques that merge the numerous players in the chain into a smoothly functioning system by improving operational efficiencies during harvest, industrial processing and transportation from farm to the ultimate consumer. Improved revenues can be generated by increasing the concentration of sugar in the harvested cane through the use of excellent agronomic practices and production management.

*Corresponding author.

${ }^{1}$ ESALQ/USP, Av. Pádua Dias, 11 - 13418-900 Piracicaba, SP, Brazil. E-mail: jose.caixeta@usp.br

${ }^{2}$ Louis Dreyfus Company, Rua Afonso Celso, 1102 apto 11B - 04119-061 São Paulo, SP, Brazil.

E-mail: andre.miyashita@gmail.com 
Strategic planning is of utmost importance when aligning chain players to realize necessary operational efficiencies. In the sugar sector, operational efficiencies begin on the farm; if the productive segment is in disarray, supply chain planning will prove futile. Decision making for harvest operations is the focus of a number studies as the harvest is an important source of costs within the chain (mechanization and transportation costs). Proper sugarcane harvest management will result in a product that has the desired sugar content to supply industry with raw materials, meeting processing requirements and arriving in a timely fashion. As a complex system, the sugarcane chain is vulnerable to external factors and there may be mismatches between the timing of the harvest and the processors demand schedule (at the industry level).

The present study addresses sugarcane harvest strategies to perform the harvesting due to crop maturation patterns.

\section{SUGARCANE: AGRICULTURE AND ECONOMICS}

Originally from Southeast Asia, Saccharum spp, also known as sugarcane, is the basic raw material for sugar and ethanol production in Brazil. It belongs to the grass family of plants and is a very efficient bio-converter turning natural resources into organic matter (Stray, 2010).

Sugar (Sacarosis) is the main product yielded from the sugarcane plant. It is accumulated inside the stalks from the bottom to the top of the plant. When the sugar content in the whole stalk reaches reasonable values (maturity peak), the cane is ready to be harvested. This physiological stage is characterized by a higher content of sugar, higher dry matter volumes and consequently a higher concentration of sucrose (Salassi et al., 2002b; Scarpari \& Beauclair, 2010).

In this context, climate has an impact in the harvest operations as rainfall negatively affects the cane stalks' sugar content and reduces workable hours. The harvest usually occurs in the dry season, when the moisture content in the harvested material is low and the Sacarosis is most concentrated.

It is important to note that the potential month of a specific sugarcane variety's peak maturity is the key variable that determines organization of the spatial divisions on a sugarcane farm. The proper organization of those divisions, called "talhões", is crucial to the optimization of farm operations. Their organization affects the efficient utilization of equipment and labor during fertilization, pest and weed control processes, soil preparation, planting, and other actions taken as the cane passes through its different physiological stages.

According to Stray (2010), besides the agricultural aspects affecting system organization and yield, there are other variables that must be considered when determining the field crop layout. Among them there are barriers and fire breaks, which are common on sugarcane farms due to the wide spread damage caused by insects, diseases, fires and water run-off after long and heavy rainfall.

The layout of the farm's talhões is strategic in that it can be used to optimize field operations by facilitating the use of equipment and the logistical flow by positioning the different crops. 
Therefore, movement between crops, from crops to roads, and from roads to processing industries, is as expeditious as possible.

Regarding the mature harvested cane yield and use by industry, Almazan et al. (1998) show into details a yield of $1,000 \mathrm{~kg}(1 \mathrm{mt})$ of cane in a standard system field (see Table 1).

Table 1 - Yield and usage of 1,000 kg of mature harvested cane.

\begin{tabular}{l|l}
\hline Mature cane in field & $1,000 \mathrm{~kg}$ \\
Volume that reaches the mill & $824 \mathrm{~kg}$ \\
Volume left in field & $94 \mathrm{~kg}$ \\
Waste from initial cleaning & $82 \mathrm{~kg}$ \\
Mill process liquid waste & $430 \mathrm{~kg}$ \\
Mud & $33 \mathrm{~kg}$ \\
Ash & $1 \mathrm{~kg}$ \\
Molasses & $26 \mathrm{~kg}$ \\
Bagass & $231 \mathrm{~kg}$ \\
Sugar & $104 \mathrm{~kg}$ \\
\hline
\end{tabular}

Source: Almazan et al. (1998).

Table 1 shows that there is a lot of sugarcane waste as it moves from the field through processing. Recent efforts have improved process efficiency, but problems (and opportunities) still exist.

According to Beauclair \& Penteado (1984), Salassi et al. (2002a), Higgins et al. (2004), Scarpari et al. (2008) and Clemente \& Almeida-Filho (2015), physiologic simulations, tactical and strategic planning to better allocate resources, and weather forecasts usually define the schedule for sugarcane planting, spraying, harvesting, transporting and processing. Items in the schedule determine the cane's Sacarosis content, which defines the timing of peak sugar and the material's quality.

\section{INDUSTRY OVERVIEW}

Most sugarcane mills are privately owned by big companies or large farmer associations (Stray, 2010). This industry is extremely concentrated, driven by international competition, large investments in necessary machinery, and high production costs. Brazil and India are key players in this market, with great volumes of cane processed by the countries' respective industries.

Starting at the beginning of the season, decision makers have to structure the system's crucial processes, which include planning the crop schedules to properly allocate resources, adjusting the workforce, procuring inputs, organizing the harvest schedule, and studying weather predictions all while taking into account mill crush capacity. The number of variables that need to be attended to is somewhat simplified because mill processes are similar (standard) between mills, with only small variations regarding equipment and some work procedures (Miller, 2008). 
Timing in the system is critical, not only to optimize the system by properly aligning peak sugar, the harvest operations, and the mill's processing capacity for cost effective operation; but to minimize the time needed to transform the crop into a commercial product as cane suffers from sugar content deterioration over time. This puts pressure on all chain processes, especially those time-consuming operations related to transportation and delays unloading at mill docks. Because of this, collaborative partnerships among industry stakeholders have been formed to better rationalize the use of logistic equipment and/or effect machine rentals to achieve gains in production scale. In a discrete event simulation for transportation and mill yard wait times, Iannoni and Morabito (2006) found that there are opportunities to decrease sugar deterioration in mill queues and other transport activities.

Brazilian sugarcane crop management presents some of the best results among the world's cane producers. Some reliable and assertive decision making processes strongly based on crop planning optimization can be found on Díaz \& Perez (2000), Stray et al. (2012), Jena \& Poggi (2013), Morales-Cháves et al. (2016), Junqueira \& Morabito (2017). Therefore, there are opportunities to study and implement research based solutions to operational issues in this type of business (Scarpari \& Beauclair, 2010).

\section{METHODS FOR HARVEST SCHEDULING}

Due to the chain's biological component, the different levels in the chain need to be tightly integrated, otherwise slowdowns occur, the cane starts to deteriorate, and sugar content is reduced. In other words, the farmer's harvest schedule and the miller's processing schedule must be strictly aligned to get the most sucrose from the processed product. Transportation and maintenance services play important roles in this integration, either facilitating or hampering the process.

The best time for harvesting is when the sugar yield is highest (sugar peak), but that time may not match industry timelines. Timely processing is quite difficult if all farms harvest at the same time. There is a trend line for sugar concentration that starts with the beginning of the harvest season up to its middle period. This entire range of time determines the sector time frame for field operations, the basis for strategic supply, demand, and operations planning.

The sugarcane business can be studied from different angles with different approaches and the use of different statistical methodology. Scarpari \& Beauclair (2010) pinpointed in a recent optimization study that addressed not only changes in classic variables included in sugarcane oriented studies, such as production capacity, workforce, and transportation distances, but expanded the analysis by including additional variables representing plant varieties and planting schedules, transportation cost, fleet size, number of trips and load capacity to carry out a more detailed investigation of the complex.

Many approaches can be used to investigate chain bottlenecks. It is possible to find published studies addressing mathematical scheduling, planning supply optimization, discrete event simulation and applied queueing theory at the mill-yard (Stray, 2010). The modeling in this paper 
will focus on operational efficiency in the field, directed toward harvesting scheduling to meet the industry timeline demand.

Linear programming (LP) algebraic expressions and spreadsheets are better used when there is a low level of locations and fewer facilities to integrate and a high level of practical applicability are involved; otherwise, simulation modeling and dynamic and mixed integer programming are recommended, especially when the planning horizon increases (Gigler et al., 2002; Röonnqvist, 2003; Higgins \& Muchow, 2003; Jiao et al., 2005). According to Loubser (2002), system and modeling simplification usually limit the validity and applicability of the model. However, it is still very clear that final users feel more comfortable when supported by mathematical models that are a bit easier to understand.

Nevertheless, one can approach the harvesting scheduling problem for sugarcane using a very simple LP modeling. Taking as an example, the hypothetical numbers presented in Table 2 and 3 related to production of sugarcane (ton) and Sacarosis content (kg/ton), per farm.

Table 2 - Production of sugarcane (ton), per farm.

\begin{tabular}{c|c|c|c|c}
\hline Farm/month & September & October & November & December \\
\hline 1 & 2050 & 2150 & 2300 & 2500 \\
2 & 3080 & 4000 & 4200 & 4300 \\
3 & 1300 & 1500 & 1600 & 1700 \\
\hline
\end{tabular}

Table 3 - Sacarosis content ( $\mathrm{kg} / \mathrm{ton})$, per farm.

\begin{tabular}{c|c|c|c|c}
\hline Farm/month & September & October & November & December \\
\hline 1 & 80 & 81 & 82 & 83 \\
2 & 64 & 72 & 65 & 60 \\
3 & 78 & 79 & 76 & 75 \\
\hline
\end{tabular}

To obtain the available total amount of Sacarosis per farm, in each month, the productivities from Table 2 can be multiplied by the values from Table 3, which will result in the values presented in Table 4.

Table 4 - Available monthly amount of Sacarosis $(\mathrm{kg})$, per farm.

\begin{tabular}{c|c|c|c|c}
\hline Farm/month & September & October & November & December \\
\hline 1 & 164,000 & 174,150 & 188,600 & 207,500 \\
2 & 197,120 & 288,000 & 273,000 & 258,000 \\
3 & 101,400 & 118,500 & 121,600 & 127,500 \\
\hline
\end{tabular}

Considering the possible combinations involving farms $(t=1,2,3)$ and months ( $c=$ September, October, November and December), 12 endogenous variables could be visualized, which will be named $Y_{t c}$. Therefore, supposing that a farm has to be totally harvested within a month, such 
variables can be treated as binary ones, i.e., the decision maker would have to choose the best month to harvest each one of the farms.

Taking as the main objective the maximization of the revenues of the commercialization of the sugarcane based on the volume of cane harvested and the level of Sacarosis, for this simple example the schedule would be: farm 1 being harvested in December, farm 2 in October and farm 3 also in December (September and November would have no harvest!). The revenue of the commercialization of the sugarcane based on the volume of cane harvested and the level of Sacarosis, for this hypothetical situation, is equal to US\$2,678,900.

Those results could also be obtained through the following mathematical structure:

$$
R=P S \times \sum_{t} \sum_{c} \sum_{i} \sum_{f} P R O_{t c} \times S A C A R_{t c} \times Y_{t c}
$$

where

$P S=$ price of Sacarosis (US\$ 4.30/kg);

$P R O_{t c}=$ production of sugarcane on farm $t$, in current month $c$ (tons);

$S A C A R_{t c}=$ Sacarosis content, measured from the maturation curve, for farm $t$, in current month $c$ (kg/ton);

$Y_{t c}=$ binary variable representing if the farm $t$ is to be harvested in current month $c$ or not.

The objective function is subject to a set of constraints related to the harvest schedule timeline by farm.

$$
\text { CRONOT AL }
$$

where:

CRONOTAL $=$ definition that the whole farm $t$ has to be harvested in one only month during the total available period of time, being:

$$
\text { CRONOTALt }=\sum_{c} Y_{t c} \quad \text { for } \quad \forall t
$$

As the sugar mill cannot stop during the season and has to work continuously (see Paiva \& Morabito, 2007), an important missing information for this initial example is the monthly industry minimum processing capacity.

Therefore, the objective function can be defined as being the maximized revenue $(R)$ in US $\$$ from the commercialization of the sugarcane volumes, accounting for the level of Sacarosis (similar to expression 1):

$$
R=P S \times \sum_{t} \sum_{c} \sum_{i} \sum_{f} P R O_{t c} \times S A C A R_{t c} \times Y Y_{t c}
$$

but where: 
$Y Y_{t c}=$ representative variable of the proportion of farm $t$ crop to be harvested in current month $c$ (not binary as $Y_{t c}$ anymore).

The objective function is subject to a set of constraints that now includes the mill's crushing capacity volume per month besides the harvest schedule timeline by farm.

a) Industry processing capacity, represented by:

$$
P R O C M E S_{c} \geq C A P_{c}
$$

where:

$P R O C M E S_{c}=$ volume in tons of sugarcane to be processed by the industry in the current month $c$, within a schedule starting at month $i$ and finishing at month $f$, where:

$$
P R O C M E S_{c}=\sum_{t} P R O_{t c} \times Y Y_{t c}
$$

$C A P_{c}=$ industry minimum processing capacity in current month $c$, in tons.

b) Harvesting scheduling per sugar farm, represented by

$$
\text { CRONOT ALt }=1.0
$$

being:

$$
\text { CRONOTAL }=\sum_{c} Y Y_{t c} \text { for } \forall t
$$

Assuming a fictitious number for the mill's crushing capacity (minimum of 1,800 ton, per month), the optimal schedule presented in Table 5 can be obtained.

Table 5 - Proportion of each farm to be harvested in a given period, assuming the mill's crushing capacity equal to 1,800 ton.

\begin{tabular}{c|c|c|c|c}
\hline Farm/month & September & October & November & December \\
\hline 1 & & & & $100 \%$ \\
2 & $47.4 \%$ & $45.0 \%$ & $7.6 \%$ & \\
3 & & & $92.5 \%$ & $7.5 \%$ \\
\hline
\end{tabular}

The monthly crushed volumes processed by the sugar mill are presented in Table 6 .

Table 6 - Monthly crushed volumes (tons) processed by the sugar mill.

\begin{tabular}{c|c|c|c}
\hline September & October & November & December \\
\hline 1800 & 1800 & 1800 & 2628 \\
\hline
\end{tabular}


The revenue of the commercialization of the sugarcane based on the volume of cane harvested and the level of Sacarosis, for this hypothetical situation, is equal to US\$ 2,559,268 (almost 5\% less than the value related to the initial harvest scheduling).

It is interesting to note that the harvesting for the three farms takes place continuously, perhaps due to the behavior of the available monthly amount of Sacarosis $(\mathrm{kg})$, per farm - or by coincidence. Anyhow, there was no specific constraint that would guarantee that the harvesting for the farms takes place continuously, which will be proposed in the following section.

\section{THE PROPOSED MODEL}

The choice of the best period for harvesting is usually guided by mill crush capacity due to high opportunity and operational fixed costs. Constraining factors associated to transportation impose additional limits harvest timing. Among these considerations are fleet availability, transportation services quality, and the high price of these services at times of extreme demand.

In view of that, a Mixed-Integer Linear Programming model (MILP) is proposed to optimize the scheduling of sugarcane harvests. The proposed model has as its main reference the structures proposed by Caixeta-Filho et al. (2002) for lily flowers and by Caixeta-Filho (2006) for citrus groves, as a means of guaranteeing as an optimal solution a continuous period for harvesting operations. Therefore, the main contribution/novelty of the proposed model is the consideration (and guarantee) - through a specific constraint - of the time continuity during harvesting operations, which is essential for the sugarcane harvest planning.

\subsection{Objective function}

Following the same basic structure of classic optimization models, the proposed model considers an objective function to be maximized, subject to several capacity and time scheduling constraints. The objective function is defined as being the maximized revenue $(R)$ in US\$ from the commercialization of the sugarcane volumes, accounting for the level of Sacarosis:

$$
R=P S \times \sum_{t} \sum_{c} \sum_{i} \sum_{f} P R O_{t c} \times S A C A R_{t c} \times Y Y Y_{t i c f}
$$

where:

$Y Y Y_{\text {ticf }}=$ representative variable of the proportion of farm $t$ crop to be harvested in current month $c$, with a schedule starting at month $i$ and finishing at month $f$.

The alternatives for the optimization of the objective function, that is, the binary endogenous variables strictly speaking, are concerned with possible harvesting schedule combinations during the harvest season. For example, if $Y_{\text {ticf }}=0.36$, farm $t$ must have $36 \%$ harvested during the current month $c$, within a period that starts in the month $i$ and finishes in the month $f$. 


\subsection{Model constraints}

The objective function is subject to a set of constraints related to the mill's crushing capacity volume per month, the harvest schedule timeline by farm and also the ones related to the obligation of respecting continuous harvesting times.

a) Industry processing capacity, represented by:

$$
P R O C M E S_{c} \geq C A P_{c}
$$

It is also understood that "Industry processing capacity" in the month $c$ (represented by $P R O C M E S_{c}$ ), covering all the possibilities within a schedule starting at month $i$ and finishing at month $f$, can also be represented in the following manner:

$$
P R O C M E S_{c}=\sum_{t} \sum_{i} \sum_{f} P R O_{t c} \times Y Y Y_{\text {ticf }}
$$

b) Harvesting scheduling per sugar farm, represented by:

$$
\text { CRONOT } A L_{t}=1.0
$$

being

$$
\text { CRONOTAL }=\sum_{i} \sum_{f} X_{t i f} \text { for } \forall t \text { and } i \leq f
$$

and $X_{\text {tif }}$ is a binary variable. For instance, if $X_{\text {tif }}=1$, farm $t$ must have its harvesting schedule starting in month $i$ and finishing in month $f$.

c) Respecting continuous harvesting times.

To guarantee consistency between the decision variables $Y Y Y_{\text {ticf }}$ and $X_{t i f}$, the following set of equations is proposed, including the attribution of a zero value for decision variable $Y Y Y_{\text {ticf }}$ when the binary variable $X_{\text {tif }}$ equals zero, avoiding inconsistent timing combinations:

$$
\begin{array}{ll}
\sum_{c} Y Y Y_{t i c f}=X_{t i f} & \text { for } i \leq f \text { and } c \geq i \text { and } c \leq f \\
X_{t i f}=0 & \text { for } i>f \\
Y Y Y_{t i c f}=0 & \text { for } i>f \text { or } c<i \text { or } c>f \\
Y Y Y_{\text {ticf }}+X_{\text {tif }} \geq(1+P R O P M I N) \times X_{\text {tif }} & \text { for } i \leq f \text { and } c \geq i \text { and } c \leq f
\end{array}
$$

Basically, equation (14) guarantees that, given an initial $(i)$ and a final month $(f)$ for the harvesting schedule of a specific farm $(t)$, the operations have to happen monthly $(c)$ within that interval $(i$ to $f$ ), in a continuous manner.

However, this type of behavior can only be observed for periods when $i \leq f$ and $c \geq i$ and $c \leq f$. For inconsistent timing combinations $(i>f$ or $c<i$ or $c>f)$, the values of $X_{\text {tif }}$ and $Y Y Y_{\text {ticf }}$ must be equal to zero (equations 15 and 16). 
PROPMIN is a parameter (expression 17) to be informed and related to the minimum acceptable harvesting proportion for the sugar farms in any month of the year (e.g., if it is assumed that a minimum proportion is $1 \%$, then $1+$ PROPMIN $=1.01$ ).

For the simple example based on data from Tables 2 and 3, the same harvesting schedule illustrated in Table 5 was obtained (as expected). Thus, such an optimization structure worked fine for what can be called "prototype" problem.

\section{APPLICATION OF THE PROPOSED MODEL}

The proposed optimization structure was tested in a broader type of environment. The input data considered in the model (see Tables 7 and 8) is based on a representative set of data consisting of sugarcane production volume $P R O_{t c}$ and the sugarcane's Sacarosis content $S A C A R_{t c}$ arranged in a matrix indexed in two dimensions:

i) $c$ : time scheduling for the current month, from 1 to 12 ;

ii) $t$ : harvested farm area, from 1 to 10 .

Table 7 - Monthly volume of sugarcane production (in ton), by farm.

\begin{tabular}{c|c|c|c|c|c|c|c|c|c|c|c|c|c}
\hline Farm & JAN & FEB & MAR & APR & MAY & JUN & JUL & AUG & SEPT & OCT & NOV & DEC & Average \\
\hline T1 & 2000 & 2005 & 2000 & 2100 & 1900 & 1940 & 1900 & 1920 & 2050 & 2150 & 2300 & 2500 & 2064 \\
T2 & 1900 & 1725 & 2050 & 1111 & 2234 & 3397 & 2404 & 1749 & 3800 & 4000 & 4200 & 4300 & 2739 \\
T3 & 1831 & 1872 & 1781 & 1693 & 1779 & 1922 & 1920 & 1906 & 1300 & 1500 & 1600 & 1700 & 1734 \\
T4 & 1926 & 1194 & 1863 & 1721 & 1975 & 1007 & 1823 & 1821 & 1700 & 1900 & 2100 & 2200 & 1769 \\
T5 & 1831 & 1872 & 1781 & 1693 & 1779 & 1922 & 1920 & 1906 & 2100 & 2200 & 2250 & 2330 & 1965 \\
T6 & 1831 & 1872 & 1781 & 1693 & 2000 & 2235 & 1655 & 1855 & 3500 & 3600 & 3700 & 3800 & 2460 \\
T7 & 1910 & 1960 & 1900 & 1850 & 1910 & 2120 & 1220 & 2100 & 2250 & 2350 & 1840 & 2500 & 1993 \\
T8 & 2000 & 2150 & 2200 & 1950 & 1900 & 2000 & 2100 & 1930 & 1800 & 2400 & 2450 & 2500 & 2115 \\
T9 & 2250 & 2200 & 2200 & 2100 & 2000 & 2100 & 2200 & 2250 & 1800 & 2400 & 2000 & 1700 & 2100 \\
T10 & 1990 & 2100 & 1910 & 1920 & 1910 & 1910 & 2000 & 2100 & 2100 & 1500 & 2250 & 1350 & 1920 \\
\hline
\end{tabular}

Table 7 shows possible harvest volumes from each farm $t$ in the model. Each number within the matrix represents a given value (collected data) for the production variable $\left(P R O_{t c}\right)$, followed by productions averages for farm $t$ and by month $c$. The last column gives the average monthly production over the year.

Considering all the differences among farms in regards to controlled and uncontrolled variables acting directly on production yield and resources combinations, a general trend is still discernable, with volumes increasing from mid-August to the end of the year (see Fig. 1).

Figure 1 shows gray bars containing the minimum and maximum production volumes of each month $c$, in all the farms. The median production volumes of each month $c$, in all the farms, 


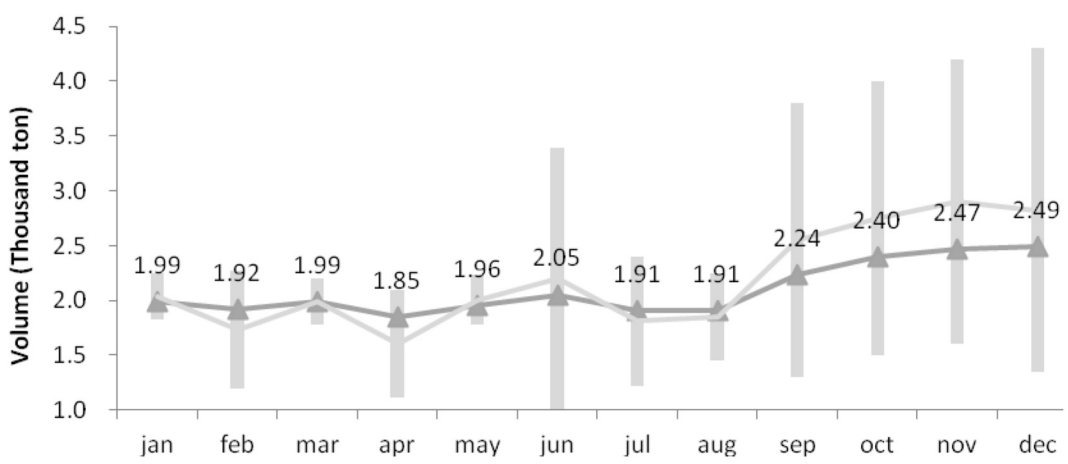

Figure 1 - Harvested volume fluctuation and production averages for all the farms, by month.

are plotted in the gray line. The (triangle) marked (green) line represents the average monthly production behavior, over the total production range.

It is possible to see that among the highest volumes averages, the production range bars are higher and the average curve is located below the median curve. From this pattern, it can be inferred that regarding the highest production months, probably not all of the farms follow this tendency. The most separated green and gray lines are, the less standardized are the presented harvested volumes in the farms.

Table 8 - Monthly Sacarosis yield (in kg/ton) by farm.

\begin{tabular}{c|c|c|c|c|c|c|c|c|c|c|c|c|c}
\hline Farm & JAN & FEB & MAR & APR & MAY & JUN & JUL & AUG & SEPT & OCT & NOV & DEC & Average \\
\hline T1 & 40 & 41 & 39 & 40 & 37 & 38 & 39 & 37 & 80 & 81 & 82 & 83 & 53 \\
T2 & 25 & 27 & 25 & 31 & 31 & 30 & 34 & 34 & 64 & 72 & 65 & 60 & 42 \\
T3 & 63 & 60 & 59 & 60 & 62 & 63 & 66 & 64 & 78 & 79 & 76 & 75 & 67 \\
T4 & 54 & 58 & 52 & 51 & 66 & 64 & 61 & 68 & 66 & 70 & 71 & 71 & 63 \\
T5 & 61 & 62 & 62 & 63 & 67 & 62 & 67 & 60 & 71 & 75 & 72 & 72 & 66 \\
T6 & 68 & 66 & 67 & 62 & 71 & 70 & 66 & 68 & 69 & 69 & 71 & 70 & 68 \\
T7 & 58 & 59 & 62 & 62 & 66 & 67 & 68 & 70 & 71 & 72 & 70 & 69 & 66 \\
T8 & 30 & 34 & 34 & 36 & 31 & 40 & 43 & 43 & 44 & 47 & 46 & 46 & 40 \\
T9 & 50 & 52 & 53 & 57 & 57 & 58 & 55 & 55 & 56 & 61 & 62 & 60 & 56 \\
T10 & 60 & 59 & 57 & 61 & 66 & 65 & 66 & 62 & 63 & 63 & 67 & 65 & 63 \\
\hline
\end{tabular}

Table 8 is a list of the cane's Sacarosis content $\left(S A C A R_{t c}\right)$ accordingly to Table 7's data matrix. The values represent the amounts $(\mathrm{kg})$ of Sacarosis in each ton of cane harvested in farm $t$ and month $c$. The last column gives the average monthly production over the year.

Figure 2 illustrates the Sacarosis contents and also presents the minimum and maximum values delimited by the gray range bar and a trend line with the same color showing where the medians of the bars are located. The (triangle) marked (green) curve represents the Sacarosis average in each month $c$, for all farms $t$. 


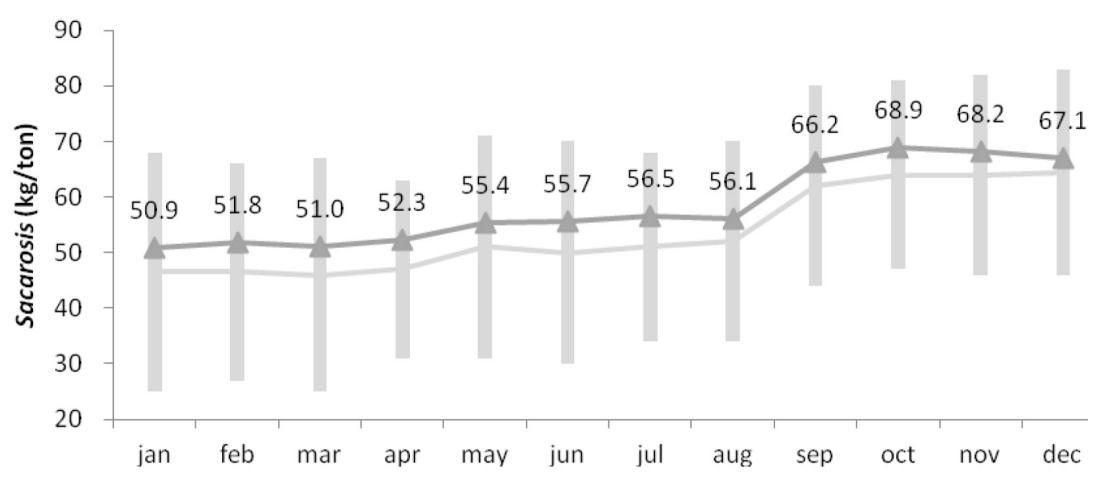

Figure 2 - Sacarosis content fluctuation for all the farms, by month.

However, Figure 2 shows a different behavior for the average curve, compared with the median curve. All the monthly averages are located above the gray trend line, which means that probably there are more values greater than a medium parameter in each month or some months have a very low value, pushing the median's curve downside.

In other words, given the data input used for this model optimization, the sampling showed an underestimate for the sugar content and an overestimate for the production volumes in May and at the end of the year.

Consistently with literature, the data set shows suitable production volumes and sugar content patterns. Barata (1992) and Scarpari \& Beauclair (2010) found similar sugar harvesting patterns in case studies for crop yield maximization, with the highest marginal values usually occurring in August, September and October.

Regarding production quantities, the observed volume peak in the month of July is caused by a common agricultural practice, to induce sugarcane maturity through the application of chemical ripeners in response to high prices paid for sugar and ethanol generally in May.

Both Sacarosis contents and production quantities represent values collected from a representative set of farms in order to validate the present study. Although sugarcane supply at the industrial level is planned on a daily basis, the data in the model is aggregated into months for comparison and application purposes and in accord with the methodology used in representative published studies (already mentioned in this article).

The São Paulo State sugarcane producers board (CONSECANA-SP), through the sugarcane industry union (Unica, 2015) maintain a central database for that Brazilian sugarcane sector, which has been used as a reference in several studies. The database contains some key parameter indicators that are normally aggregated by month.

Although the capacity input in the present model is a unique value for all the months $c$, this input could also be a matrix of tailored mill capacity values for each current month $c$. In the same way, the fluctuating price paid for the Sacarosis could also be captured according to measured or 
forecasted values. However, this established price can certainly change and with it the revenues and the objective function value in the analysis, but it will not change the model's outputs pattern.

\subsection{Analyzed scenarios}

All of the data as well as the proposed model were processed using the GAMS optimization package (Brooke et al., 1998). The solver used was IBM ILOG CPLEX 24.9.1 (r63795 Released Aug 30, 2017 VS8 x86 32bit/MS Windows - GAMS/Cplex 12.6.3.0), licensed for continuous and discrete problems.

Following the model structure developed in this study, various scenarios were considered, differing among them regarding the variation of the minimum acceptable proportion of the farm's cultivatable area to be harvested (PROPMIN), from 1 to 50 percent (expression 17).

The main output from these analyses can be seen in Figure 3. The graph there captures the variation from 1 to $50 \%$ of the PROMIN factor (with all the farms being analyzed together) and the corresponding impact in the value of the objective function (the revenue $-R-$ in US\$ from the commercialization of the sugarcane volumes, accounting for the level of Sacarosis). Scenarios with values above $50 \%$ for this minimum proportion were not considered because they presented infeasible solutions for this model.

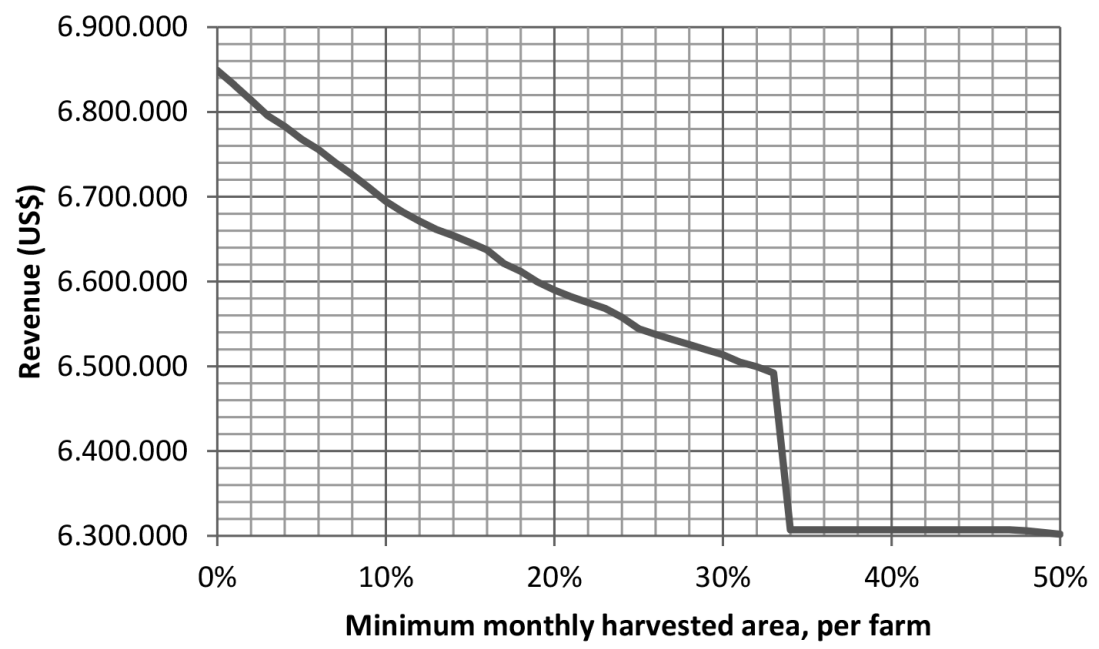

Figure 3 - Value of the objective function (maximized revenue - "R" - in US\$) constrained by the minimum monthly harvested area, per farm ("PROPMIN" factor, in \%).

Table 9 brings the details of the schedules obtained for farm T10, showing a very clear pattern of continuity for the harvesting operations for PROPMIN from 1 to 50\% (note that for PROPMIN $=0$, this represents the possibility of a discontinuous calendar for that farm, which in such a case is represented by a harvesting schedule involving only February and August). 
Table 9 - Optimal schedules obtained for farm T10, varying the minimum monthly harvested area ("PROPMIN" factor, in \%) from $0 \%$ to $50 \%$.

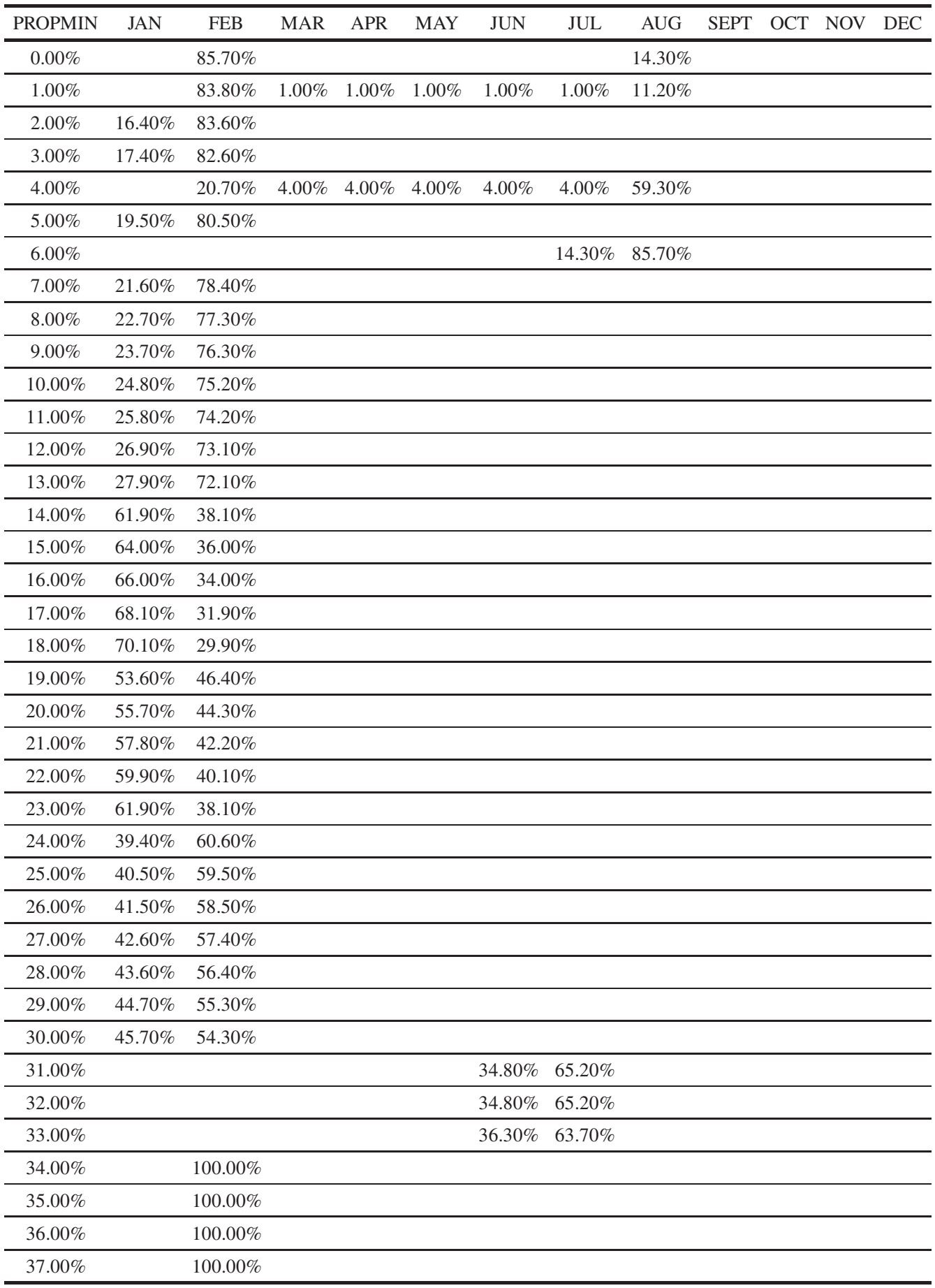


Table 9 - (Continuation)

\begin{tabular}{|c|c|c|c|c|c|c|c|c|c|c|c|c|}
\hline PROPMIN & JAN & FEB & MAR & APR & MAY & JUN & JUL & $\overline{\mathrm{AUG}}$ & SEPT & OCT & NOV & $\overline{\mathrm{DEC}}$ \\
\hline $38.00 \%$ & & $100.00 \%$ & & & & & & & & & & \\
\hline $39.00 \%$ & & $100.00 \%$ & & & & & & & & & & \\
\hline $40.00 \%$ & & $100.00 \%$ & & & & & & & & & & \\
\hline $41.00 \%$ & & $100.00 \%$ & & & & & & & & & & \\
\hline $42.00 \%$ & & $100.00 \%$ & & & & & & & & & & \\
\hline $43.00 \%$ & & $100.00 \%$ & & & & & & & & & & \\
\hline $44.00 \%$ & & $100.00 \%$ & & & & & & & & & & \\
\hline $45.00 \%$ & & $100.00 \%$ & & & & & & & & & & \\
\hline $46.00 \%$ & & $100.00 \%$ & & & & & & & & & & \\
\hline $47.00 \%$ & & $100.00 \%$ & & & & & & & & & & \\
\hline $48.00 \%$ & & $100.00 \%$ & & & & & & & & & & \\
\hline $49.00 \%$ & & $100.00 \%$ & & & & & & & & & & \\
\hline $50.00 \%$ & & $100.00 \%$ & & & & & & & & & & \\
\hline
\end{tabular}

The more flexible scenarios achieve higher revenues from operations, with the discontinuous scenario resulting in the highest revenue among all scenarios. The discontinuous scenario revealed to be the best scenario when considering only revenue values, being $8.68 \%$ greater than the most restrictive scenario of a 50 percent minimum harvested area.

It is possible to calculate a sort of "elasticity" relating the change in the minimum proportion to its effect in the decrease of the revenue. For the behavior of the curve presented in Figure 3 (from 0 to $33 \%$ ), the average elasticity can be calculated as $0.16 \%$, which means that - in average an increase of $1 \%$ in the minimum area harvested for all the farms together ("PROPMIN") will result a decrease of $0.16 \%$ in the maximum total revenue.

When the farms are analyzed together, a clear pattern of results can be seen immediately after the 33 percent level. Above this point, the ending month of the harvest is the same as the beginning month (except for T2 and T6 farms). In other words, when the minimum area to be harvested is more than $33 \%$ of the total area, all of the harvest operations within the studied farm should be completed in the same period.

This 33 percent value has implications for the decision maker in the sugarcane chain. This means that when less than 33 percent of the total area is harvested, the revenues from sugar commercialization will be higher. Therefore, at a given total production cost, the decision maker can decide whether it is feasible or not to operate in some specific range of gains.

To illustrate different patterns of harvesting calendars, Tables 10 and 11 reproduce the continuous schedules for all the farms, with PROPMIN being equal to $12 \%$ and $50 \%$, respectively. It is interesting to note that for PROPMIN $=12 \%$, one can find harvesting along 26 time windows; on the other hand, with a lower revenue, for PROPMIN $=50 \%$, one can find only 12 harvesting time windows. 
Table 10 - Continuous harvesting schedules, all the farms, with PROPMIN being equal to $12 \%$.

\begin{tabular}{|c|c|c|c|c|c|c|c|c|c|c|c|c|}
\hline Farm & JAN & FEB & MAR & APR & MAY & JUN & JUL & AUG & SEPT & OCT & NOV & DEC \\
\hline $\mathrm{T} 1$ & & & & & & & & & & & & $100.00 \%$ \\
\hline $\mathrm{T} 2$ & & & & & & & & & & $78.80 \%$ & $21.20 \%$ & \\
\hline $\mathrm{T} 3$ & & & & & & $29.70 \%$ & $12.00 \%$ & $58.30 \%$ & & & & \\
\hline $\mathrm{T} 4$ & & & $12.00 \%$ & $12.00 \%$ & $76.00 \%$ & & & & & & & \\
\hline $\mathrm{T} 5$ & & & $30.60 \%$ & $69.40 \%$ & & & & & & & & \\
\hline T6 & & & & & & & & $12.00 \%$ & $51.40 \%$ & $12.00 \%$ & $24.60 \%$ & \\
\hline $\mathrm{T} 7$ & & & $14.40 \%$ & $12.00 \%$ & $15.70 \%$ & $58.00 \%$ & & & & & & \\
\hline $\mathrm{T} 8$ & & & & & & & $75.80 \%$ & $24.20 \%$ & & & & \\
\hline T9 & $56.20 \%$ & $12.00 \%$ & $31.80 \%$ & & & & & & & & & \\
\hline $\mathrm{T} 10$ & $26.90 \%$ & $73.10 \%$ & & & & & & & & & & \\
\hline
\end{tabular}

Table 11 - Continuous harvesting schedules, all the farms, with PROPMIN being equal to $50 \%$.

\begin{tabular}{|c|c|c|c|c|c|c|c|c|c|c|c|c|}
\hline Farm & JAN & FEB & MAR & APR & MAY & JUN & JUL & AUG & SEPT & OCT & NOV & DEC \\
\hline $\mathrm{T} 1$ & & & & $100.00 \%$ & & & & & & & & \\
\hline $\mathrm{T} 2$ & & & & & & & & & $50.00 \%$ & $50.00 \%$ & & \\
\hline $\mathrm{T} 3$ & & & & & & $100.00 \%$ & & & & & & \\
\hline $\mathrm{T} 4$ & & & & & $100.00 \%$ & & & & & & & \\
\hline T5 & $100.00 \%$ & & & & & & & & & & & \\
\hline $\mathrm{T} 6$ & & & & & & & & & & & $50.00 \%$ & $50.00 \%$ \\
\hline $\mathrm{T} 7$ & & & & & & & & $100.00 \%$ & & & & \\
\hline $\mathrm{T} 8$ & & & & & & & $100.00 \%$ & & & & & \\
\hline T9 & & & $100.00 \%$ & & & & & & & & & \\
\hline $\mathrm{T} 10$ & & $100.00 \%$ & & & & & & & & & & \\
\hline
\end{tabular}

As it was already mentioned, the expression (17) of the proposed optimization modeling structure considers the parameter PROPMIN, which represents the minimum monthly harvested area (in \%), per farm. Therefore, PROPMIN $=0$ is a picture illustrating non-continuous harvesting times, simulating the case where harvesters are able to operate regardless of their operating cost and schedule. From a practical point of view, this scenario requires a great number of available harvesters and good field crop positioning. Table 12 brings the harvesting calendars for all the farms, with PROPMIN = 0, i.e., any proportion of the sugar farms is eligible to be harvested at any time and operations can be started and finished as many times as needed.

For this discontinuous scenario, the model seeks to maximize revenue from sugar commercialization based mainly on Sacarosis content. This results in a maximized objective function with possible alternative optimal solutions giving the same higher revenue.

This theoretical scenario only would be possible if the activity's operational efficiency is not taken into account. However, this type of harvest scheduling should be analyzed as it shows 
Table 12 - Discontinuous harvesting calendars for all the farms (PROPMIN =0).

\begin{tabular}{|c|c|c|c|c|c|c|c|c|c|c|c|}
\hline Farm & JAN & FEB & MAR & APR & MAY JUN & JUL & AUG & SEPT & OCT & NOV & DEC \\
\hline $\mathrm{T} 1$ & & & & & & & $100.00 \%$ & & & & \\
\hline $\mathrm{T} 2$ & & & & & & & $99.99 \%$ & $0.01 \%$ & & & \\
\hline $\mathrm{T} 3$ & & & & & & $53.70 \%$ & $46.30 \%$ & & & & \\
\hline $\mathrm{T} 4$ & & & & & $91.10 \%$ & & $8.90 \%$ & & & & \\
\hline $\mathrm{T} 5$ & $65.40 \%$ & & & $34.60 \%$ & & & & & & & \\
\hline $\mathrm{T} 6$ & & & & & & & $51.40 \%$ & & $48.60 \%$ & & \\
\hline $\mathrm{T} 7$ & & & & & & $36.30 \%$ & & $63.70 \%$ & & & \\
\hline $\mathrm{T} 8$ & & & $56.70 \%$ & & & & $43.30 \%$ & & & & \\
\hline T9 & $21.70 \%$ & & $25.20 \%$ & $53.10 \%$ & & & & & & & \\
\hline $\mathrm{T} 10$ & & $85.70 \%$ & & & & & $14.30 \%$ & & & & \\
\hline
\end{tabular}

the maximum potential revenues from the considered system at a given sugar price, industry capacity and farm production volume (strictly speaking, when the continuous scheduling option is disabled, the optimal model recommends harvesting each fragment of area within the farm only when the cane reaches peak sugar content).

If there are not enough harvesters and the field is not properly laid-out, harvest could not be carried at any time to maximizes either production yield or Sacarosis content. In view of that, the economies of having the right equipment utilization and transportation from the farm can be benchmarked by the difference in the revenue between a discontinuous and a continuous way of organizing the timing of the sugarcane maturation.

\section{CONCLUDING REMARKS}

Optimization has become a popular topic for numerous agricultural studies given its relevance in almost all economies. The current study contributes to literature devoted to sugarcane sector optimization by exploring continuous sugarcane harvesting operations, giving information and insights that the decision maker can use to maximize profits.

The main achievement of this study is to demonstrate how a given sugarcane farm's harvest scheduling can change when operations must follow a continuous calendar under variations of a minimum operational proportion of areas being harvested or when operations are discontinuous within a year.

The findings presented in this study show that sugar content $(\mathrm{kg} / \mathrm{ton})$, due to the accumulation of Sacarosis in the cane stalks, represents the main driver for optimization of proposed model's objective function.

Regarding the minimum harvested proportions, it is possible to see that the greater the proportion of the total land that is to be harvested at one time (the more restrictive scenarios), the more condensed the harvest schedule becomes. This means that harvest operations should primarily 
focused on months during which the cane has higher Sacarosis contents. When using some sort of discontinued harvest approach, priority is given to harvests when the crop reaches its highest sugar content, respecting all other constraints but not necessarily considering continuous periods. Analyzing all the scenarios, potential revenue gains reached $8.68 \%$ when moving from the most restrictive scenario to the discontinuous one. Another important finding is that there was a breaking point when the minimum proportion of harvested area increased to 33 percent that led to reduced revenues. From the harvesting perspective, the model output shows a one pattern up to this percentage, and from this percentage and above another pattern is established.

These values have implications for the chain's decision makers as they give them estimates that can be employed to calculate revenues resulting from the use of different harvest scheduling configurations after taking into consideration the chain's structure and affected production, operational, and transactional costs.

The present model is also versatile in a way that it is applicable to other sets of sugarcane farms and also to other agriculture crops since the corresponding data can be adapted to capture crop life cycles. The obtained results can also be useful for the evaluation of the feasibility of movement of equipment during harvesting operations.

For teaching purposes, this article - which can be considered as a simple application of the model - may be used as an exercise in undergrad or even in graduation studies of Operations Research courses.

The model has some structural limitations. Oscillations in nominal industry processing capacity and prices paid for the commodity are not taken into account by the model. Also, it is not common in Brazil to have harvesting operations during the initial months of the first semester (those months were considered in this article - who knows if this "paradigm" can be questioned?). In further studies, those facts could be treated and properly tested.

\section{REFERENCES}

[1] Almazan O, Gonzalez L \& Galvez L. 1998. Maurice Paturau Memorial Lecture, Keynote Address, The sugar cane, its by-products and co-products. In: Proceedings of the Third Annual Meeting of Agricultural Sciences, University of Mauritus, Reduit, Mauritus.

[2] BARATA MQF. 1992. Otimização econômica do corte e reforma de canaviais. Agricultural Engineering Dissertation. University of São Paulo, Piracicaba, Brazil.

[3] Beauclair EgF \& Penteado CR. 1984. Cronograma de corte da cana-de-açúcar através da programação linear. Seminário da Tecnologia Agronômica, 2: 424-434.

[4] Brooke A, Kendrick D, Meeraus A \& Raman R. 1998. GaMS: a user's guide. The Scientific Press, San Francisco (USA).

[5] CAiXeta-Filho JV. 2006. Orange harvesting scheduling management: a case study. Journal of the Operational Research Society, 57(6): 637-642.

[6] Caixeta-Filho JV, Van Sway Neto JM \& Wagemaker AP. 2002. Optimization of the Production Planning and trade of Lily Flowers. Interfaces, January-February, 32(1): 35-46. 
[7] Clemente TRN \& Almeida-Filho AT. 2015. An approach to financial risk in a portfolio for planning the industrial production of products derived from sugarcane. Pesquisa Operacional, 35(3): 599-615.

[8] DíAz JA \& PÉREz IG. 2000. Simulation and optimization of sugar cane transportation and harvest season. In: Proceedings of the 2000 Winter Simulation Conference: 1114-1117.

[9] Gigler JK, Hendrix EMt, Heesen RA, van den Hazelkamp VGW \& Meerdink G. 2002. On optimisation of agri chains by dynamic programming. European Journal of Operational Research, 139(3): 613-625.

[10] Higgins AJ \& Muchow RC. 2003. Assessing the potential benefits of alternative cane supply arrangements in the Australian sugar industry. Agricultural Systems, 76(2): 623-638.

[11] Higgins AJ, Sandell G, Davies I, Prestwidge D \& Andrew B. 2004. A framework for integrating a complex harvesting and transport system for sugar production. Agricultural Systems, 82(2): 99-115.

[12] IAnnoni AP \& Morabito R. 2006. A discrete simulation analysis of a logistics supply system. Transportation Research Part E: Logistics and Transportation Review, 42(3): 191-210.

[13] Jena S \& Poggi M. 2013. Harvest planning in the Brazilian sugar cane industry via mixed integer programming. European Journal of Operational Research, 230(2): 374-384.

[14] Jiao Z, Higgins AJ \& PRestwidge DB. 2005. An integrated statistical and optimisation approach to increasing sugar production within a mill region. Computers and electronics in agriculture, $\mathbf{4 8}(2)$ : $170-181$.

[15] JUNQUEIRA RAR \& MORABito R. 2017. Optimization approaches for sugarcane harvest front programming and scheduling. Gestão e Produção, June, 24(2): 407-422.

[16] Loubser RC. 2002. Model for estimating effects of harvesting practices on factory output. Proc. S. Afr. Sugar Technol. Assoc., 76: 42-50.

[17] Miller LC. 2008. Planejamento e Operacionalização da colheita de cana-de-açúcar. http://www.sigacana.com.br/d_COLHEITA/4.PLANEJ_E_OPER_DA_COLHEITA_ DE_CANA_INDUSTRIAL_atualiz.htm. Accessed in November 28, 2015.

[18] Morales-Chávez MM, Soto-Mejía JA \& SARACHe W. 2016. A mixed-integer linear programming model for harvesting, loading and transporting sugarcane: a case study in Peru. DYNA, February, 83(195): 173-179.

[19] Paiva RPO \& Morabito R. 2007. Um modelo de otimização para o planejamento agregado da produção em usinas de açúcar e álcool. Gestão e Produção, Jan-Apr, 14(1): 25-41.

[20] RöonnqVist M. 2003. Optimisation in forestry. Math. Program., 97(1-2): 267-284.

[21] Salassi ME, Breaux JB \& NAQuin CJ. 2002a. Modeling within-season sugarcane growth for optimal harvest system selection. Agricultural Systems, 73(3): 261-278.

[22] Salassi Me, Champagne LP \& Legendre BL. 2002b. Maximizing economic returns from sugarcane production through optimal harvest scheduling. J. Am. Soc. Sugarcane Technologists, 22: $30-44$.

[23] SCARPARI MS \& BEAUCLAIR EGF. 2010. Optimized agricultural planning of sugarcane using linear programming. Investigación Operacional, 31(2): 126-132. 
[24] Scarpari MS, Plà LM \& Beauclair EGF. 2008. La optimización del cultivo de variedades de caña de azúcar. Investigación Operacional, 29(1): 26-33.

[25] StRay BJ. 2010. Tactical sugarcane harvest scheduling. PhD Thesis. Stellenbosch: University of Stellenbosch.

[26] Stray BJ, van Vuuren J \& Bezuidenhout CN. 2012. An optimisation-based seasonal sugarcane harvest scheduling decision support system for commercial growers in South Africa. Computers and Electronics in Agriculture, 83: 21-31.

[27] UNICA. 2015. Consecana. http://www. unica.com.br/consecana/. Accessed in: November $28,2015$. 